\title{
P02.67. An alternative for Chronic Fatigue Syndrome, an observational case series
}

\author{
H Woodfield ${ }^{1 *}$, M Dickholtz Sr. ${ }^{2}$, B Bell ${ }^{3}$, L Jacobs ${ }^{3}$ \\ From International Research Congress on Integrative Medicine and Health 2012 \\ Portland, Oregon, USA. 15-18 May 2012
}

\section{Purpose}

Chronic Fatigue Syndrome (CFS) has an elusive diagnosis and etiology. Treatment focuses on alleviation of symptoms and improving a patient's quality of life. The primary objective was to observe and record changes in a subject's health related quality of life (HRQoL), using the SF 36Item Health Survey (SF-36), before and six months after a National Upper Cervical Chiropractic Association (NUCCA) atlas correction. The Pittsburgh Sleep Quality Index (PSQI) was used to observe changes in a subject's sleep quality.

\section{Methods}

Nineteen subjects diagnosed as having CFS according to the 1994 Centers for Disease Control and Prevention (CDC) diagnostic criteria were studied. Patients who were fatigued six (6) or more months and who met four (4) or more diagnostic criteria were psychiatrically evaluated, and then underwent lab testing and SPECT imaging. Data collection and study administration were conducted using a practice-based research-based protocol. Patients were monitored for a period of six months to insure Atlas alignment was maintained and then retested.

\section{Results}

SF-36 results at the end of the study, by a paired t-test of SF-36 data $(n=19)$ revealed a significant increase in the General Health component, from 30.3 pre to 60.9 post $(\mathrm{p}<0.03)$, and in the Mental Health component, from 68.6 to $74.7(\mathrm{p}<0.02)$. The overall PSQI score significantly decreased from 12.1 to $6.1(\mathrm{p}<0.05)$. SPECT scans and lab testing were inconclusive.

'Upper Cervical Research Association, Bellingham, USA

Full list of author information is available at the end of the article

\section{Conclusion}

If correction of atlas misalignment in clinically diagnosed CFS patients is the single variable that appears responsible for self-reported improvement of functional and mental health status, then further study is warranted to determine the utility of this intervention in patient care. The study was limited by the lack of a control group and that care was provided by only one practitioner.

\section{Author details}

${ }^{1}$ Upper Cervical Research Association, Bellingham, USA. ${ }^{2}$ National Upper Cervical Chiropractic Association, Monroe, USA. ${ }^{3}$ Advocate Good Shepherd Hospital, Barrington, USA.

Published: 12 June 2012

doi:10.1186/1472-6882-12-S1-P123

Cite this article as: Woodfield et al.: P02.67. An alternative for Chronic

Fatigue Syndrome, an observational case series. BMC Complementary and Alternative Medicine 2012 12(Suppl 1):P123.

Submit your next manuscript to BioMed Central and take full advantage of:

- Convenient online submission

- Thorough peer review

- No space constraints or color figure charges

- Immediate publication on acceptance

- Inclusion in PubMed, CAS, Scopus and Google Scholar

- Research which is freely available for redistribution 